\title{
Prevalence of New Onset Anosmia in COVID-19 Patients: Is The Trend Different Between European and Indian Population?
}

\author{
Prasun Mishra $^{1} \cdot$ Vishwanath Gowda $^{1} \cdot$ Shivani Dixit $^{1} \cdot$ Maitri Kaushik $^{1}$
}

Received: 9 June 2020/Accepted: 16 July 2020/Published online: 21 July 2020

(C) Association of Otolaryngologists of India 2020

\begin{abstract}
COVID-19 outbreak is major pandemic affecting lakhs of people all across the globe. Along with other nonspecific clinical features, reports mention anosmia to be an important symptom in COVID-19 positive patients. To study the prevalence of anosmia in confirmed COVID-19 patients, in Indian population and to ascertain its significance as a symptom of COVID 19. Study was done at a tertiary care COVID treating hospital. While eliciting detailed history from Covid-19 positive patients, all patients were asked about symptom of anosmia. Same was asked from control group of subjects who were COVID-19 negative. The history of anosmia was also elicited on discharge after the patients tested negative for COVID-19. 74 patients formed part of the study. 11 of 74 (14.8\%) patients had anosmia. On using the chi square test for significance the difference was significant $(p<.01)$, suggesting anosmia to be a significant clinical feature in COVID-19 patients. On comparing with world literature it was observed that the prevalence of anosmia is higher in European population as compared to Indian Also the symptom of anosmia improved when the patient recovered from the disease. Prevalence of new onset anosmia in Indian population with COVID-19 is $14.8 \%$. Symptom of
\end{abstract}

Prasun Mishra

entprasun@gmail.com

Vishwanath Gowda

vishwamg09@gmail.com

Shivani Dixit

shivanidixit918@gmail.com

Maitri Kaushik

Maitri.kaushik@gmail.com

1 Department of ENT, Bharati Vidyapeeth Medical College, Pune 411046, India anosmia in present times should be considered as a important clinical feature and should raise a suspicion of COVID-19. The prevalence of anosmia in Indian population is much lesser than that reported in European population.

Keywords COVID-19 · Anosmia - Corona virus · Atypical $\cdot$ Symptoms $\cdot$ Indian

\section{Introduction}

In the month of December 2019, pneumonia cases were identified in the Hubei province of China [1]. This disease caused by novel corona Virus was later declared as a public health emergency and a pandemic by WHO [2]

The main clinical features of this disease are cough fever, generalized malaise, and myalgia. These features are mainly like those of influenza [3]. Interestingly most expressions of COVID-19 are non-specific [4]. Anosmia has also been reported as one of such nonspecific clinical features in multiple studies $[5,6]$.

Tyrell and Bynoe, in 1966, first cultivated coronavirus in patients of common cold. This was alpha corona virus and caused very mild symptoms.[7]. However SARS-Cov-2 causing COVID-19 disease is a beta coronavirus and does cause severe respiratory symptoms $[8,9]$.

Coronavirus as an organism is known to cause loss of smell along with symptoms of common cold [10]. The initial literature from China did not mention much about anosmia as a an important suspect or presenting symptom of COVID-19. Recent literatures especially from European countries do mention about anosmia to be important feature in these patients [5, 11]. In April 2020, literature search showed, anosmia as clinical feature in a multicentric cohort 
study on patients with COVID-19 [5, 6], some even reporting anosmia to be present in as high as half of patients with COVID-19 [12].

India, as a country with huge population has also seen a upsurges in Covid-19 case after mid-march. This study aims to describe the prevalence of anosmia in confirmed COVID-19 patients, in Indian population and whether the presence of this is significant symptom of COVID 19.

\section{Materials and Methods}

This study was performed at the tertiary care hospital dedicated for treating Covid-19 cases. An expedited institutional ethical committee clearance was taken. All patients who were Covid-19 test positive and having mild to moderate symptom, not admitted in ICU, formed part of the study group. A written informed consent was taken from all the patients to be part of this study. To put on records all patients were willing to be part of study. Patients more than 12 years of age were included in the study. Exclusion criteria consisted of patients with previous history of nasal surgery, known case of allergic rhinitis, sinusitis, nasal polyposis, major head injury, or any chronic nasal disease. Patients having anosmia before the diagnosis of Covid-19 were also excluded. Besides the main complaints all patients were asked about presence or absence of anosmia (loss of smell). With the same exclusion criteria another group of subjects who were COVID-19 negative were asked about presence or absence of anosmia. Care was taken to keep the age in both the groups matched to avoid any bias

The COVID positive patients who had anosmia were contacted again after when they tested negative and history of anosmia was elicited again.

The data was recorded in excel sheet and analyzed.

\section{Results}

Data was collected from a total of 74 patients in the COVID ward. 31 were females and 43 were males (Fig. 1). In the control group 29 subjects were female and 45 were male.

The patients were divided in five age groups to understand if age distribution. The distribution of patients in each group was as per Table 1 .

Out of total 74 patients from whom data was collected 11 patients had Anosmia. Thus $14.8 \%$ of all positive patients has symptom of anosmia (Fig. 2). none of the controls had symptoms of anosmia only one subject had hyposmia. Thus the prevalence of Anosmia in COVID-19 patients was $14.8 \%$

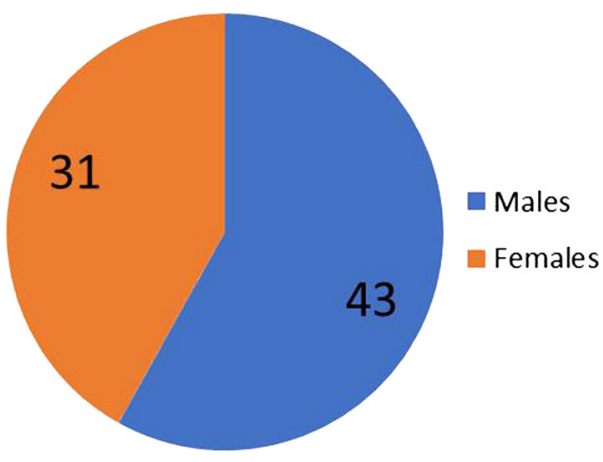

Fig. 1 Gender distibution of COVID-19 positive patients

Table 1 Age distribution in the COVID-19 group and the control group

\begin{tabular}{lll}
\hline $\begin{array}{l}\text { Age } \\
\text { groups }\end{array}$ & $\begin{array}{l}\text { COVID-19 positive } \\
\text { group }\end{array}$ & $\begin{array}{l}\text { Controls (COVID-19 } \\
\text { negative) }\end{array}$ \\
\hline$<20$ & 13 & 14 \\
$20-30$ & 17 & 15 \\
$31-40$ & 16 & 15 \\
$41-50$ & 18 & 15 \\
$>51$ & 10 & 15 \\
\hline
\end{tabular}

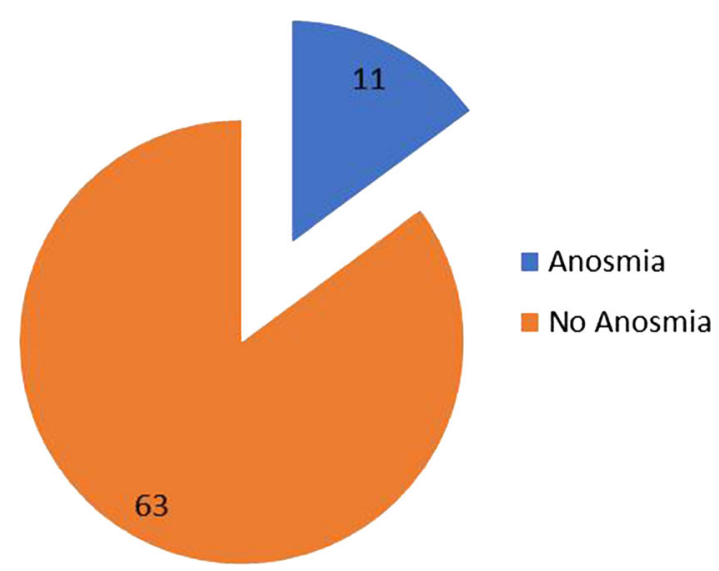

Fig. 2 Patients with anosmia in COVID-19 positive patients

To study the significance of presence of Anosmia in COVID-19 positive patients A chi-square test of independence was performed.

The relation between these variables was significant, $\mathrm{X} 2$ $(1, \mathrm{~N}=74)=9.35 p=.0022$. Suggesting that COVID-19 patients are more likely to have anosmia then controls who were COVID-19 negative.

As a protocol after COVID-19 negative test at the end of 14 days the patients were discharged. On discharge $7 / 11$ patients had regained the sense of smell. The patients were 
contacted on telephone at the end of 21 days and all the patients had regained their sense of smell by then.

\section{Discussion}

COVID-19 outbreak is major pandemic affecting lakhs of people all across the globe not only disrupting the global health situation, but also destabilizing the world economy.

Fever along with respiratory signs and symptoms are more or less well established clinical features of this disease [4]. Reports suggest that absence of fever may be more frequent in patients of COVID 19 as compared to SARS-CoV and MERS-CoV [13]. Thus if case definition focuses on fever then there is a chance that surveillance team may miss out certain patients $[14,15]$. Interestingly most expressions of COVID-19 are non-specific [4]. Anosmia has also been reported as one of such nonspecific clinical features in multiple studies [5, 6] and Lechien et al. [16] in their multicentric European study have reported 357 patients with olfactory dysfunction related to COVID-19.

Viral upper respiratory infection (URI) is since long known as one of the major commonly identified causes of olfactory dysfunction $[17,18]$.

A recent study by Sungnak et al. [19] suggested that nasal epithelial cells show a high angiotensin converting 2 (ACE2) expression in SARS-CoV-2 infection, and thus this may allowing wide viral entry. Thus anosmia can be a possible atypical feature of COVID-19 patients.

In the present study 74 COVID-19 patients were evaluated for presence of anosmia and out of the 11 patients (14.8\%) had symptoms of anosmia while in controls that were COVID-19 negatives none had anosmia only one subject had hyposmia. Thus the prevalence of anosmia in COVID-19 patients in present study was $14.8 \%$.

As compared to study by Klopfenstein the prevalence is less as they reported anosmia in $47 \%$ of their patients [12]. Also Lechien et al. [16] reported anosmia in as high as $86 \%$ of their patients. Not much data about Asian population as available suggesting anosmia to be an important symptom

Few questions need to be answered regarding possible reason for difference in anosmia prevalence rates between European and Asian population. There might be mutation of the virus surface protein, spike $S$ protein and nucleocapsid $\mathrm{N}$ protein, providing stability to the virus preventing its entry into the cell [20].

Ethnic and racial difference and its role in virus affecting specific system more can be another area of research to explain the potential difference in prevalence.

Another possible reason for the difference could be the difference in expression level of ACE2 in different tissues which might affect the susceptibility, symptoms, and outcomes of COVID-19 infection [21].
The present study also compared the symptom of anosmia between COVID-19 positive patients and COVID19 negative controls so find out the significance of presence of this symptom. It was found that the difference in two groups was significant $(p<.01)$. Thus though the prevalence of anosmia in Indian populating is less compared to that of European, anosmia does form a important clinical feature in patients of COVID-19.

Definitely many questions need to be answered as this is a new virus with number of mutation and varied clinical pattern in different parts of world. However every drop of knowledge will help us clinicians to understand, diagnose and treat this condition better.

This study is first Indian study to study the prevalence of anosmia in COVID-19 patients.

\section{Conclusion}

Prevalence of new onset anosmia in Indian population with COVID-19 is $14.8 \%$. On comparing with controls this difference is significant and thus symptom of anosmia in present times should be considered as an important clinical feature and should raise a suspicion of COVID-19. This anosmia improved completely on recovery. The prevalence of anosmia in Indian/Asian population is much lesser than that reported in European population.

\section{Compliance with Ethical Standards}

Conflict of interest The authors declare that they have no conflict of interests.

Ethical Approval Institutional ethical committee clearance: taken.

Informed Consent Taken from all subjects.

\section{References}

1. Huang C, Wang Y, Li X et al (2020) Clinical features of patients infected with 2019 novel coronavirus in Wuhan, China. Lancet 395:497-506

2. World Health Organization. Coronavirus disease (COVID-19) outbreak. https://www.who.int. Accessed 11 Mar 2020

3. Wu Z, McGoogan JM (2020) Characteristics of and important lessons from the coronavirus disease 2019 (COVID-19) outbreak in China: summary of a report of 72,314 cases from the Chinese Centre for Disease Control and Prevention. JAMA 323(13):1239-1242. https://doi.org/10.1001/jama.2020.2648

4. Chen N, Zhou M, Dong X, Qu J, Gong F, Han Y et al (2020) Epidemiological and clinical characteristics of 99 cases of 2019 novel coronavirus pneumonia in Wuhan, China: a descriptive study. Lancet 395:507-513

5. Gane SB, Kelly C, Hopkins C (2020) Isolated sudden onset anosmia in COVID-19 infection. A novel syndrome? Rhinology 58(3):299-301. https://doi.org/10.4193/Rhin20.114 
6. Vaira LA, Salzano G, Deiana G, De Riu G (2020) Anosmia and ageusia: common findings in COVID-19 patients. Laryngoscope 130(7):1787. https://doi.org/10.1002/lary.28692

7. Tyrrell DA, Bynoe ML (1966) Cultivation of viruses from a high proportion of patients with colds. Lancet 1(7428):76-77

8. Velavan TP, Meyer CG (2020) The COVID-19 epidemic. Trop Med Int Health TM IH 25(3):278-280

9. Gilani S, Roditi R, Naraghi M (2020) COVID-19 and anosmia in Tehran, Iran. Med Hypotheses. https://doi.org/10.1016/j.mehy.2 020.109757

10. Hummel T, Whitcroft KL, Andrews P et al (2017) Position paper on olfactory dysfunction. Rhinology 56(1):1-30. https://doi.org/1 0.4193/Rhin 16.248

11. Marinosci A, Landis BN, Calmy A (2020) Possible link between anosmia and COVID-19: sniffing out the truth. E Eur Arch Otorhinolaryngol. https://doi.org/10.1007/s00405-020-05966-0

12. Klopfenstein T, Toko L, Royer PY, Lepiller Q, Gendrin V, Zayet S (2020) Features of anosmia in COVID-19. Médecine et Maladies Infectieuses. https://doi.org/10.1016/j.medmal.2020.04.006

13. Zumla A, Hui DS, Perlman S (2015) Middle East respiratory syndrome. Lancet 386:995-1007

14. World Health Organization (2020) Clinical management of severe acute respiratory infection when novel coronavirus (2019$\mathrm{nCoV}$ ) infection is suspected: interim guidance. World Health Organization, Geneva

15. Guan WJ, Ni ZY, Hu Y, Liang WH, Ou CQ, He JX, Liu L, Shan H, Lei CL, Hui DS, Du B et al (2020) Clinical characteristics of coronavirus disease 2019 in China. N Engl J Med 382:1708-1720. https://doi.org/10.1056/NEJMoa2002032

16. Lechien JR, Chiesa-Estomba CM, De Siati DR, Horoi M, Le Bon SD, Rodriguez A et al (2020) Olfactory and gustatory dysfunctions as a clinical presentation of mild-to-moderate forms of the coronavirus disease (COVID-19): a multicentre European study. Eur Arch Otorhinolaryngol 277(8):2251-2261. https://doi.org/1 0.1007/s00405-020-05965-1

17. Seiden AM (2004) Postviral olfactory loss. Otolaryngol Clin N Am 37:1159-1166

18. Suzuki M, Saito K, Min WP et al (2007) Identification of viruses in patients with postviral olfactory dysfunction. Laryngoscope 117(2):272-277. https://doi.org/10.1097/01.mlg.0000249922.37381.1e

19. Sungnak W, Huang N, Bécavin C, Berg M (2020) HCA lung biological network. SARS-CoV-2 entry genes are most highly expressed in nasal goblet and ciliated cells within human airways. https://arxiv.org/abs/2003.06122v1. Accessed 24 Mar 2020

20. Benvenuto D, Giovanetti M, Ciccozzi A, Spoto S, Angeletti S, Ciccozzi M (2020) The 2019-new coronavirus epidemic: evidence for virus evolution. J Med Virol 92(4):455-459

21. Li W, Zhang C, Sui J, Kuhn JH et al (2005) Receptor and viral determinants of SARS-coronavirus adaptation to human ACE2. EMBO J 24(8):1634-1643

Publisher's Note Springer Nature remains neutral with regard to jurisdictional claims in published maps and institutional affiliations. 